\title{
DEVELOPMENT OF THE METALS ELECTROCHEMICAL CharaCteristics Determining MeTHOD at Cathode Polarization
}

\author{
Olga Ivanova, Anna Rodkina, Vadim Kramar, Veronika Dushko
}
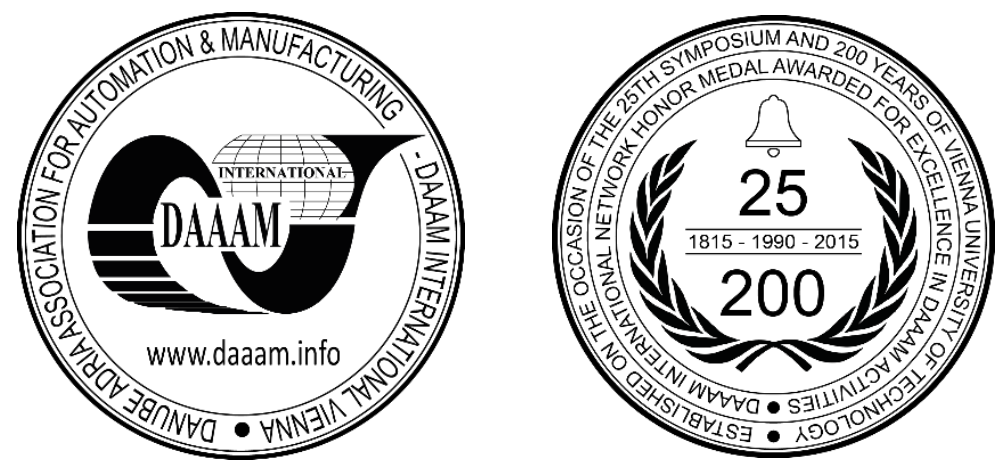

This Publication has to be referred as: Ivanova, O[lga]; Rodkina, A[nna]; Kramar, V[adim] \& Dushko, V[eronika] (2018). Development of the Metals Electrochemical Characteristics Determining Method at Cathode Polarization, Proceedings of the 29th DAAAM International Symposium, pp.0515-0522, B. Katalinic (Ed.), Published by DAAAM International, ISBN 978-3-902734-20-4, ISSN 1726-9679, Vienna, Austria

DOI: $10.2507 / 29$ th.daaam.proceedings.074

\begin{abstract}
During the research, the authors, using the hierarchy analysis method, made a choice of the method for studying the metal surface under cathodic polarization. A technique for studying metals without surface oxide films has been developed, which corresponds to the state of the metal surface at the tip of a crack or other local defect. The substantiation of a choice of the reference electrode necessary for carrying out of researches is presented. Deficiencies of the existing production technology of porous silver chloride reference electrodes are determined, a laboratory base for their production is developed. The obtained reference electrodes are necessary while investigating the potentials of steels under cathodic polarization, which is especially important for determining the parameters of protection against corrosion-mechanical to sea vessels and structures with a long service life of about 50 years. The main task of the further research is to ensure the protection of steel in sea water from general corrosion, as well as from local corrosion-mechanical destruction. Necessary results can be achieved by applying the obtained values of the potential as protective in the systems of cathodic protection of sea vessels and structures by impressed current, providing the potential of an uncharged steel surface.
\end{abstract}

Keywords: reference electrode; cathodic polarization; corrosion; sea vessels and structures; impressed current

\section{Introduction}

The development of hydrocarbon deposits on the seas and ocean continental shelf requires the creation of metalintensive offshore structures for the extraction of oil and gas [1], [2], [3], [4], [5], whose service life is more than 30 years. As the long-term practice of exploitation shows, such metal structures have intense corrosion damage caused by the action of fast moving sea water and mechanical loads, which are stress concentrators and under certain conditions can lead to the destruction of products due to low corrosion fatigue strength. The reason for this is the presence of local defects on the metal surface, which are developed by the action of the aggressive electrolyte - sea water. Vessels, ships and structures of the shelf are usually protected against corrosion by means of electrochemical protection (cathodic protection by impressed current). 
However, it must be taken into account that the protective electrochemical potential is customarily established, based only on the initial potential of the metal surface with the oxide film, which does not ensure the prevention of corrosion on the juvenile surface, i.e. in the apex of local defects. Thus, the purpose of the study is to develop a method for determining the electrochemical characteristics of metals under cathodic polarization, which makes it possible to regulate the values of the protective potential of cathodic protection of sea vessels and structures.

Research objectives are:

- to determine the most effective method for investigating the metal surface under cathodic polarization;

- to develop a method for conducting polarization investigations of metals, identifying the most promising reference electrode for research.

\section{Choice of the method for investigation the metal surface under cathodic polarization}

Parameters of the cathodic polarization by the electric current of shipbuilding steels under cathodic protection are described in many guidance materials and literature: the shift of the steel potential from stationary in seawater by $0.05-$ $0.1 \mathrm{~V}$ [6], by $0.2-2.15 \mathrm{~V}$ [7] is a condition for preventing corrosion in seawater. According to GOST 26501.85 [8], the protective potential of the ship hull can vary from -0.75 to $-0.95 \mathrm{~V}$. Taking into account the negative effect of local defects, cracks on the rate of failure of the objects, it is also necessary to take into account the value of the metal potential at the apex of such defects, that is, without an oxide film. In the course of the study, the authors have experimentally obtained the values of such potentials, but without cathodic polarization [9], [10]. To select a method for studying the metal surface under cathodic polarization, the method of analyzing hierarchies is applied prior to the beginning of its conduct [11], [12].

The first stage of the problem was structured as a hierarchy, the goal of the optimization problem "The choice of the method for investigation the metal surface under cathodic polarization" was set, the criteria for choosing the method of investigation were determined: K1 - Accuracy of the experiment, K2 - Difficulty of conducting, K3 - Instrument Park, K4 - Time resource, and a list of alternatives to research methods was also compiled: A1 - Mathematical modeling of the process, A2 - Laboratory experiment consisting in breaking the metal and examining the fracture section [13], A3 Laboratory experiment consisting in continuously metal surface-renewall during the entire experiment.

The second stage on the principle of discrimination and comparative judgments, by constructing a matrix of pairwise comparisons of the second level, was a pairwise comparison of the criteria in order to establish the priorities for the selection criteria of the research method, identifying the most important one. Then the priority vector for the matrix of pairwise comparisons was calculated as follows, the geometric mean in each row of the pairwise comparison matrix was calculated, the values obtained were summarized, then the vector of local priorities was calculated, and the results were normalized. Analysis of the results of the calculation of the priority vector for the matrix of pairwise comparisons of the second level revealed the following sequence of criteria in order of decreasing their weight: the instrument cluster, the accuracy of the experiment, the complexity of the conduct, the time resource. We believe that the weight of the criterion "time resource" is negligible, its weight is $4.5 \%$ of the total weight of the criteria.

The third stage was a pairwise comparison of research methods alternatives, to prioritize the criteria and evaluate each of the alternatives according to the criteria for selecting the research method, identifying the most important one, thus determining the optimal method for studying the metal surface under cathodic polarization. Four matrices (by the number of criteria for choosing the method of investigation) were constructed for the matrix of pairwise comparisons of the third level and four priority vectors of the corresponding matrices were calculated. The results of the step of calculating the priority vector for matrices of pairwise comparisons of the third level are analyzed. According to the total number of the first, second and third places occupied by each alternative, "The laboratory experiment, consisting of the continuous renewal of the metal surface throughout the experiment", has superiority over the other proposed methods. The next step was to analyze the contribution of the criteria for this method, which showed that the criterion "Time resource" made the largest contribution to the evaluation of this alternative.

Thus, on the basis of the hierarchy analysis method, three possible methods for studying the metal surface under cathodic polarization were analyzed. The results of the analysis showed that the most effective is the " Laboratory experiment consisting in continuously metal surface-renewall during the entire experiment".

\section{Method of conducting polarization investigations of metals}

The electrochemical parameters of various metals samples with an oxide film are determined using a potentiostat and a flatbed recorder in the potential region of an uncharged surface. The main criterion for electrochemical protection is the potential of steel displaced by applying an electric current to the cathode region (in the negative direction). The steel potential is set relative to the reference electrode, which has a stable in time potential in sea water. The given potential of the steel is maintained by a potentiostat connected to an electrochemical cell, the connection scheme is shown in Figure 1.

An electrochemical cell is assembled with a three-electrode system consisting of a working electrode, a reference electrode, with respect to which the potential of the working electrode and the auxiliary electrode is measured, forming a circuit with the working electrode through which the polarization current passes. It can be seen from Fig. 1 that the driving voltage is applied to one input of the amplifier, and on the other - the potential difference between the reference electrode and the working electrode. 
Input voltages in the amplifier are compared, and the resulting difference controls the output current of the amplifier, polarizing the working electrode to the potential set on the source of the driving voltage. Figure 2 presents a schematic diagram of polarization studies.

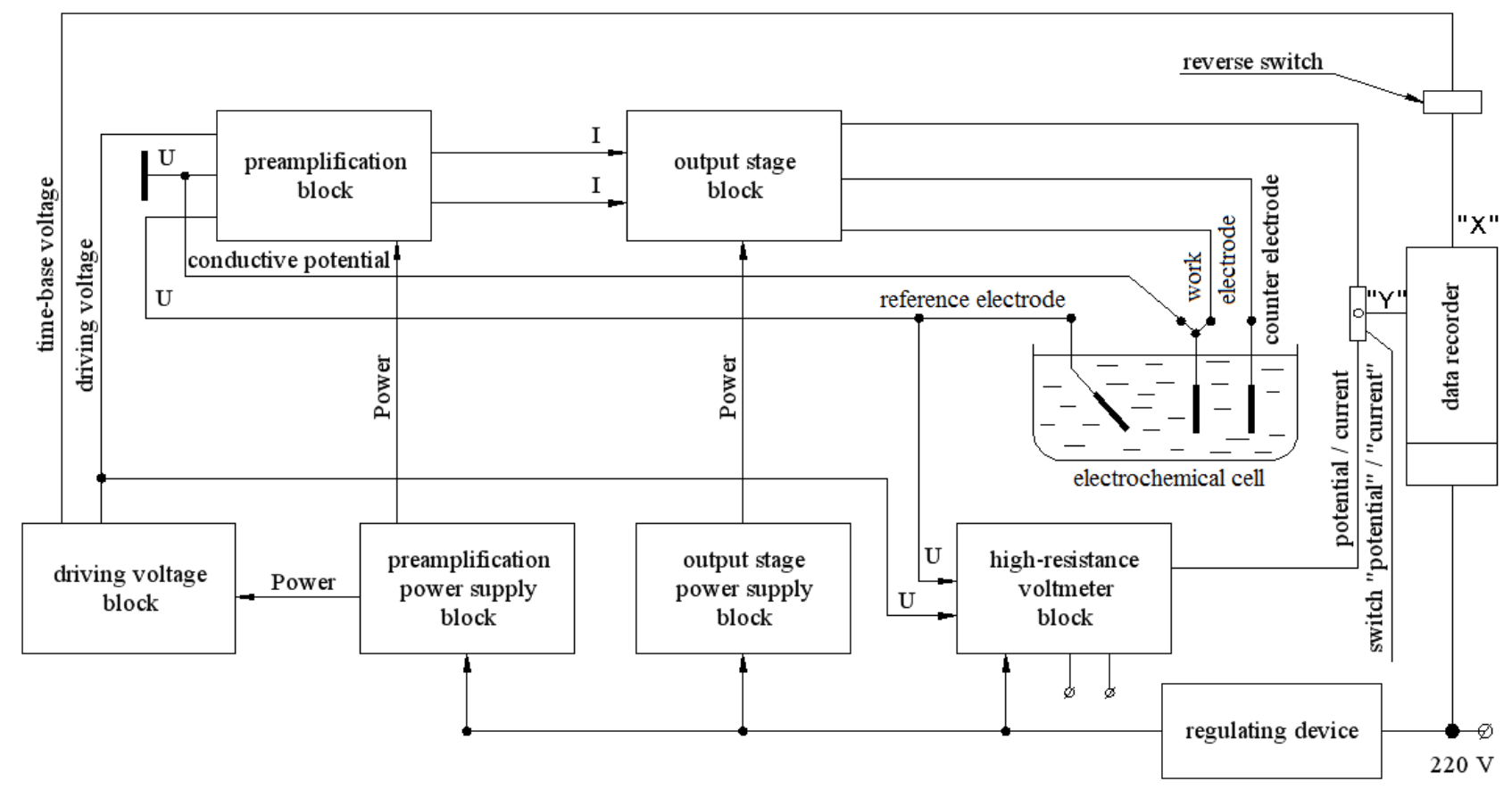

Fig. 1. Structural diagram of connecting the potentiostat and an electrochemical cell

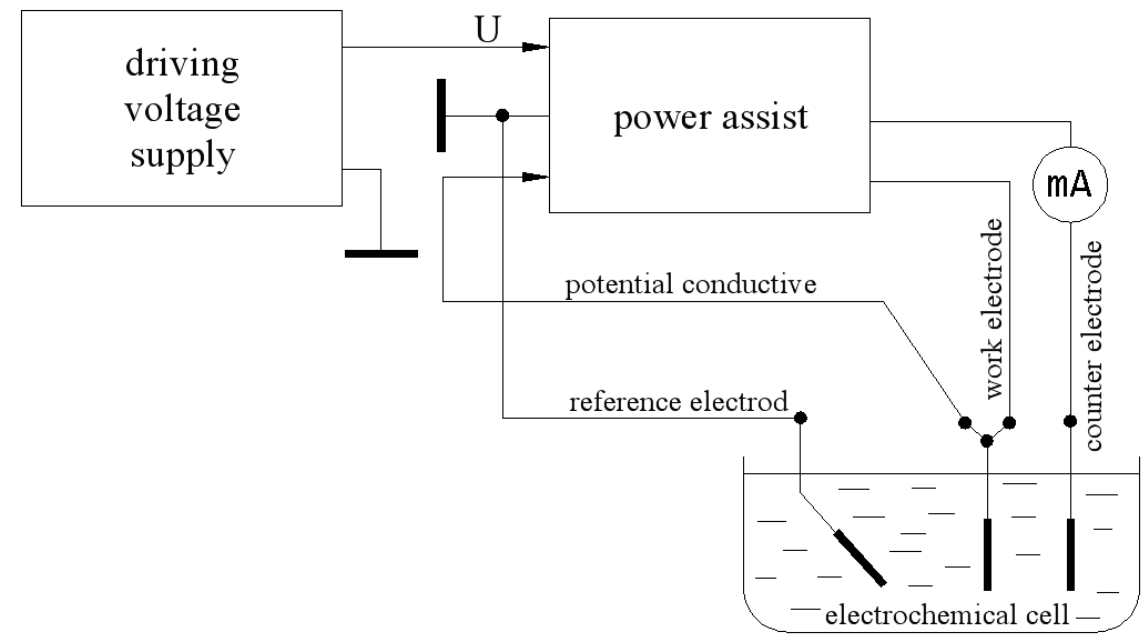

Fig. 2. Schematic diagram of polarization investigations

The potential of the electrodes (steel) and the voltage drop in the interelectrode gap are measured using the potentiostat unit intended for this purpose and relative to a reference electrode having a stable in time potential in sea water. From the available chemical comparison electrodes it was not possible to use them in studies of metals without surface oxide films because of a number of the following reasons:

- the body of the chemical electrode of comparison ES-2 is made of glass, which is inadmissible due to the presence of dynamic loads;

- the shape of the electrode body does not allow using it under experimental conditions;

- $\mathrm{KCl}$ solution contained inside the glass bulb, the hole at the end of the reference electrode, through which the $\mathrm{KCl}$ solution enters the electrolyte solution, will certainly affect the results of the experiments.

The silver chloride reference electrode is most suitable for carrying out polarization studies of metals without surface oxide films, however, due to the need to maintain the potential in a narrow region, this electrode does not provide the necessary accuracy of the potential measurement, since earlier in its manufacture, volatile carbonate was used as a volatile filler ammonium [14], the dispersion of which could not be controlled in the working mixture. 
Accordingly, the true surface of the finished electrode remained unknown, i. e. it was not possible to control the true current density. When manufacturing a silver chloride reference electrode, in accordance with [15] (CRE), a screened fraction is used as a volatile filler. As a result, the accuracy of obtaining the active surface of the silver chloride electrode is $0.001 \%$. Therefore, to determine the potential of the metals studied without a surface film, a silver chloride reference electrode was made, which was performed according to [15].

The main property of the reference electrode is non-polarizability, that is, the ability to maintain a fixed interfacial potential jump when the magnitude of the flowing current and external conditions change. A reference electrode that meets these requirements does not exist. The main standard reference electrode is a normal hydrogen electrode (NHE). Since this electrode is inconvenient for practical work, other reference electrodes are commonly used. Such reference electrodes should have a low-potential potential, the magnitude of which (relative to NHE) is known with an accuracy close to $1 \mathrm{mV}$. In some cases of electrolysis with a controlled potential, it is sufficient to know the potential of the working electrode during electrolysis with an accuracy of $10-20 \mathrm{mV}$, since the change in the potential at different points of the electrode is exactly this value; so you can use less accurate electrodes, whose potential is known with an accuracy of 10 $\mathrm{mV}$. In principle, any electrode, on the surface of which an electrochemical reaction with a high exchange current occurs, can be used as a reference electrode. The ideal reference electrode should be stable, non-polarizable, easy to handle, temperature independent, should have low resistance and parasitic capacitance, do not contaminate the test solution.

The stability of the electrode potential is very important. Instability can be caused by several reasons. One of the components may be unstable in a given solvent. For example, mercury chloride is unstable in acetonitrile, and the calomel electrode is unreliable in this solvent. Evaporation of the solvent from the standard solution, the concentration of which determines the potential, changes the potential of the reference electrode. The interfacial potential may change, this occurs when an aqueous calomel electrode connected to the test solution by means of a salt bridge containing potassium chloride and agar-agar is used to measure the potentials in acetonitrile for more than 5 minutes.

An unpolarized electrode is an electrode whose potential does not change appreciably when a small current density passes through it. Many devices for measuring the potential take a small current from the reference electrode, which depends on the resistance of the circuit. Polarization is reduced when using a reference electrode in which an electrode reaction with a high current of exchange flows, as well as when using an electrode with a large surface and a sufficiently high concentration of potential-determining particles, so that the concentration does not change appreciably when the current passes.

In some comparison electrodes, the concentration of potential-detecting particles is kept constant by applying a saturated solution of the corresponding compound. The solubility of the compound usually depends on the temperature, and for these electrodes the temperature dependence of the potential is stronger than in other types of comparison electrodes.

The contact between the reference electrode and the test solution requires special discussion. The ohmic resistance of the electrical contact should be as low as possible. It should also avoid contamination of the test solution from the reference electrode, and vice versa. As a rule, some types of salt bridges with or without a diaphragm are used. The interfacial potential is reduced if a salt such as $\mathrm{KCl}$ is used with an approximately equal mobility of the cation and anion. Diffusion between the two half-cells is suppressed using semipermeable membranes, for example a salt-saturated agar gel, a porous glass plate, an asbestos fiber or a porous glass membrane. In this case, a considerable ohmic resistance appears in the system, which must be taken into account when selecting the internal resistance of the device that measures the potential. In most cases, devices with electrometric inputs are used to measure the potential, which have an extremely high input resistance.

Comparison electrodes are divided into several types depending on the electrode reaction ensuring the constancy of the potential: in electrodes of the first kind, the potential of the electrode metal is determined by the concentration of metal ions; in electrodes of the second kind the potential is determined by the concentration of the anion forming an insoluble salt with the metal cation. In oxidation-reduction electrodes (redox electrodes), the potential of an indifferent electrode is determined by the relative concentration of the two components of the oxidation-reduction system.

Given the above reasons for the impossibility of using a standard chemical reference electrode, the silver chloride reference electrode was improved. From the methods of making the comparison electrodes the most efficient from the position of electrochemistry, sufficiently strong, simple in design, the most widely used method was the production of a silver chloride porous reference electrode. The most widely used electrode found in the composition of $65 \%$ silver, $20 \%$ silver chloride and $15 \%$ volatile ammonium carbonate.

A serious danger for chlorine-silver open comparison electrodes is the poisoning of the working surface by products present in seawater and, as a consequence, a change in the potential of the electrode.

This danger is counteracted by two factors:

- anodic polarization of the electrode in cathodic protection systems (i.e., dissolution of the reference electrode surface) and continuous updating thereof;

- a large measuring anode current, leading to the destruction of electrodes. In the reference electrode, the permissible current is $40 \mu \mathrm{A}$.

The use of measuring instruments for capacity monitoring can lead to the use of low-resistance instruments. In this case, the current may be higher than the anodic dissolution of the reference electrode will be accelerated. 
To prevent accelerated dissolution of the reference electrodes, their true emptiness in the pores can be increased by a factor of 1.5 , which will allow an increase in the admissible current up to $80 \mu \mathrm{A}$. This is achieved by adding the weight of the volatile substance to $30 \%$ compared with the accepted $15 \%$.

A certain drawback of the existing technology is the use of a volatile ammonium carbonate filler, the dispersion of which changes when introduced into the formulation and its mixing. In this case, there is no porosity control during manufacture, and this does not ensure stability in the current achieved and possible poisoning by the electrode during long-term operation. In other words, the volatile filler must have a stable shape and size, which will allow stabilizing the composition of the electrodes (their properties in mass production). The most effective is the use of a volatile filler from the polymer mass, due to the following:

- a small mass of matter due to a foamed structure;

- the possibility of sifting the mass through a set of sieves to the desired value and ensuring a stable porosity of the electrode;

- the availability of reliable experimental data on the volatilization of the polymer mass heated to $400-500{ }^{\circ} \mathrm{C}$, which show complete removal of carbon dioxide and prevents possible contamination of the composition.

The technology of manufacturing electrodes consists in pressing the composition: silver powder $50 \%$, powder silver chloride $20 \%$, polymeric mass screened by a screen with a cell up to $50 \mu \mathrm{m}, 30 \%$ and subsequent sintering at $450{ }^{\circ} \mathrm{C}$.

According to the patent [15], which proposes a new improved composition of the silver chloride reference electrode, which has a number of advantages:

- the pore-forming agent increases the true working surface of the electrode with unchanged dimensions and allows an increase in the working anode current to $80 \mu \mathrm{A}$;

- the composition is stabilized by the number and quality of the pores in the electrode;

- it becomes possible to calculate the area of the wetted surface of the electrode and, therefore, to determine the exact protection parameters.

The production of a porous silver chloride reference electrode is performed in several stages:

1. Preparation of the mixture for pressing;

2. Preparation of current lead;

3. Pressing the electrode (figure 3);

4. Burning;

5. Check of working capacity;

6. Packaging.

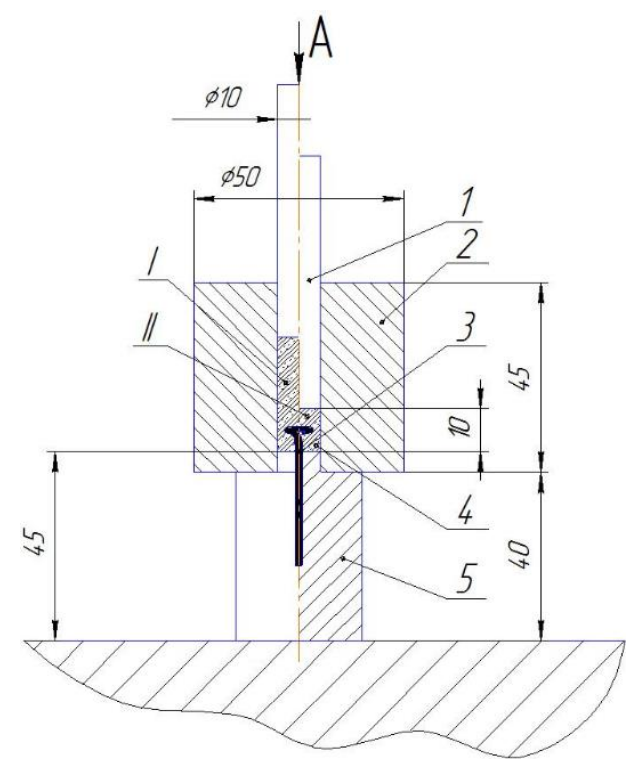

Fig. 3. Drawing of the mold and the scheme of the pressing process

The first and second stages are carried out according to the procedure described below.

Silver with heating (up to $70-80{ }^{\circ} \mathrm{C}$ ) is dissolved in nitric acid, until saturation. Top up with $10 \%$ water. Add ammonium sulfate $80 \mathrm{~g} / \mathrm{dm}^{3}$. Electrodes are stainless steel. The surface of the cathode is smooth and flat. The cathode current density depends on the concentration of silver in the electrolyte. It is experimentally to set the current to be such that, when it increases, darkening (blackening) of the precipitate takes place, the so-called. "Sunburn". The precipitate formed on the cathode during electrolysis must be shaken off (knocked down, scraped). As the appearance of "fume" gradually reduce the current. When the formation of sediment stops, the electrolyte is considered to be spent and can be sent for processing. It must be drained to a filter (the filtrate is recycled - evaporation, recovery of silver residues). The silver that has fallen on the filter must be returned to the container. 
The silver precipitate is thoroughly rinsed in distilled water, dried in a drying cabinet. Weigh the dry residue. Grind in a mortar. Transfer to a non-transparent light container. Record the weight of silver. Keep away from light. Ammonium carbonate is cooled to $0{ }^{\circ} \mathrm{C}$. Cool the mortar. Shred in it the ammonium carbonate. Sieve it on a sieve with a side opening size of not more than $100 \mu \mathrm{m}$. Weigh. Place in a closed container. Close tightly. Record the weight. Put in a cold place with a temperature below $10{ }^{\circ} \mathrm{C}$. Styrofoam is polished on fine sandpaper. Sieve on a sieve with the size of the side of the hole is not more than 100 microns. Weigh. Place in a closed container. Close tightly. Record the weight. Then the components are mixed. Preparation of current lead. Degrease silver wire $0.2 \mathrm{~cm}$ in diameter, $50-60 \mathrm{~mm}$ in length in sodium carbonate. Rinse in distilled water. Carry out surface activation in nitric acid. Rinse in distilled water. Leave the straight end of the wire $30 \mathrm{~mm}$ long. The remaining part of the wire is bent with a spiral with a ring diameter of $0.5-0.7$ $\mathrm{mm}$. The length of the spiral is not more than $20 \mathrm{~mm}$.

The third stage consists of two stages: the initial stage of pressing (I in Figure 1) and the final stage of pressing (II in Figure 1); and produced on a special mold (Figure 1), which consists of:

1. the upper punch;

2. matrix;

3. wire diameter $0.2 \mathrm{~mm}$ (silver);

4. the compressible material;

5. the bottom punch.

Pressing the electrode. Check for moisture and cleanliness of the mold. Lower the straight part of the current lead into the hole of the lower punch. Do up the matrix on the lower punch. Fill the mixture in the matrix. Blend the mixture in portions. To compress the upper punch with a small load, sufficient to put the whole mixture in the mold. Install the upper punch in the die. Place the matrix with punches into the press. Press with load up to 2 tons.

The fourth stage. The electrode should be weighed and placed in a porcelain crucible. Install in the muffle furnace. The calcination temperature for ammonium carbonate is $150{ }^{\circ} \mathrm{C}$ for 1 hour. The firing temperature for polystyrene is $350{ }^{\circ} \mathrm{C}$ for 1 hour, so the electrode is fired in a muffle furnace at $350{ }^{\circ} \mathrm{C}$ for one hour (but until the foam and dark plaque disappear). Weigh the electrode.

The fifth and the sixth stage consist in checking the working capacity and are carried out in the following order. Prepare solutions of sodium chloride with a concentration of $1 \%$ and $3 \%$. Withstand the electrode for at least three days in each solution. Maintain capacity monitoring ( 2 measurements per day). The potentials are measured by a standard chlorine silver reference electrode. The potential of the electrode should remain stable in solutions with different concentrations of sodium chloride. The permissible vibrations are $\pm 1 \%$. Weigh the electrode. Estimate water saturation. Electrode after immersion in solution, store only in solution. Avoid drying.
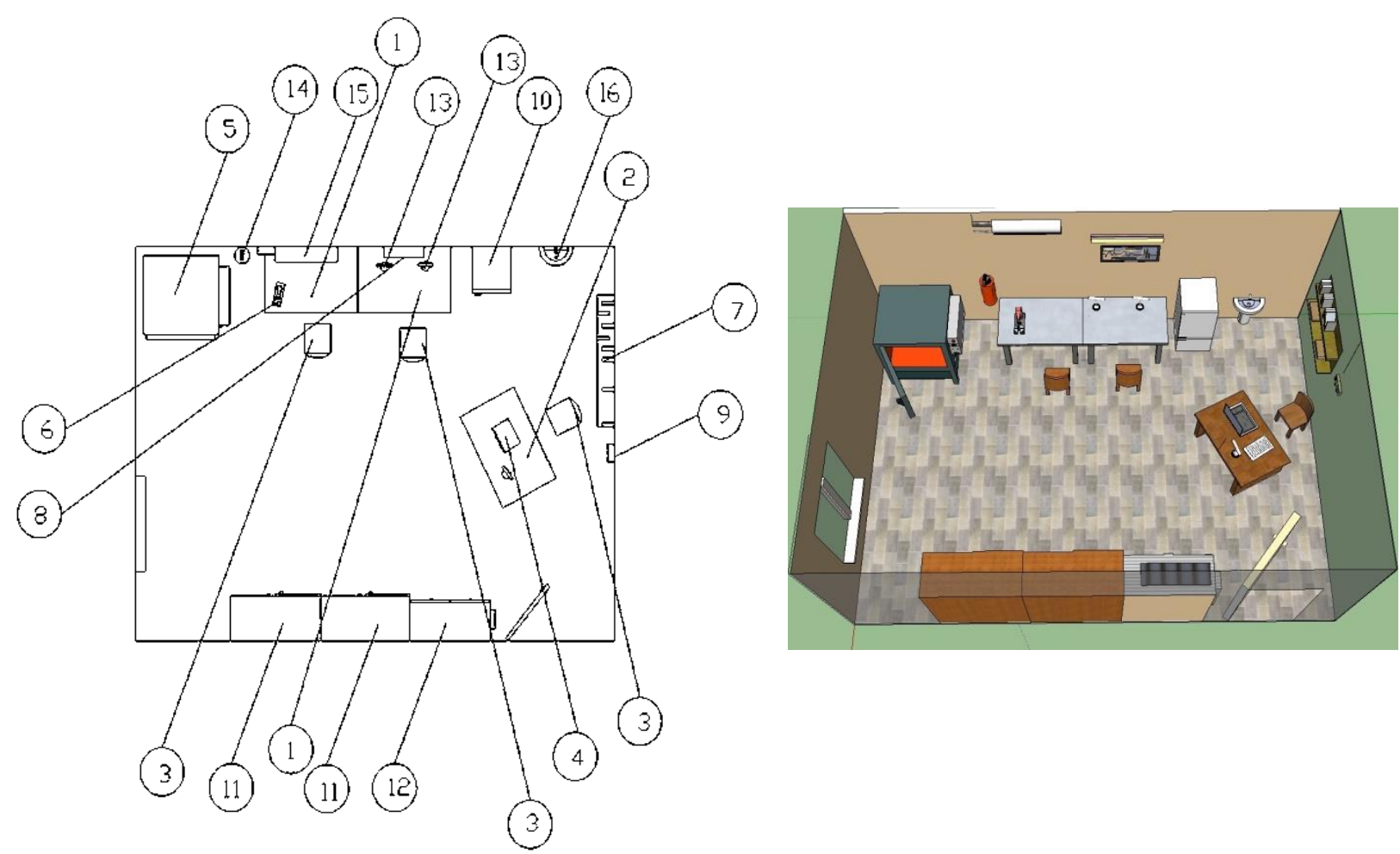

Fig. 4. Laboratory base for creating a silver chloride reference electrode 
According to the patent [15], a laboratory base was developed for realization of all stages of manufacturing of CRE (Figure 4). Necessary equipment and equipment: laboratory table (1); work desk (2); working chair (3); computer (4); muffle furnace SNOL 73/600 (5); manual press PR-2 (6); shelf with technical documentation (7); Luminescent lamp 60 W (8); the fire safety sensor (9); refrigerator Indesit ST 145 (10); a cabinet for storage of inventory and chemical utensils (11); safe deposit box (12); table lamp (13); fire extinguisher (14); general ventilation system (15); the sink (16).

However, a study of the effect of corrosion on the potential of a metal with an oxide film under cathodic polarization is not sufficient to ensure the protection of steel in seawater from local corrosion-mechanical fractures. It is necessary to determine the electrochemical characteristics on the juvenile surface of the metal. Carrying out of the given researches is possible with application of the device for creation of a freshly formed metal surface [9], [16].

\section{Method for determining the electrochemical characteristics of metals under cathodic polarization}

In order to determine the correct values of the protective potential indicated in the cathodic protection systems of sea vessels and structures by impressed current to prevent local corrosion and mechanical damage, a method has been developed for determining the potential of the metal surface without the oxide film under cathodic polarization, and thus it is possible to predict the potential of steel with the oxide film and the steel potential without an oxide film under cathodic polarization. Equipment required for the experiment: potentiostat-galvanostat; installation for creating the juvenile surface; constant current source; working electrode; different types of steels; porous silver chloride reference electrode [15]; auxiliary electrode; voltmeter.

The potentiostat-galvanostat makes it possible to investigate the metal surface with both an oxide film and without an oxide film under cathodic polarization conditions. The installation for creating the juvenile surface allows of the metal to determine the metal potential without an oxide film (surface, which simulates the state of the apex of the local fracture). A laboratory switching power supply provides a stable supply current. Carbon, alloyed and corrosion-resistant shipbuilding steels are used as work electrode. A porous silver chloride reference electrode is used [15]; auxiliary electrode required for cathodic polarization of the work electrode. A voltmeter is used to monitor the potential on the metal surface. Investigation of the surface oxide films effect on the steel potential is carried out in the condition of a model solution of sea water.

The laboratory experiment is carried out with the following sequence of actions: the work electrode is immersed in an electrochemical cell with a model solution, held in it until a steady-state potential is established, after which the installation for creating the juvenile surface that continuously removes the oxide film is started, and cathodic polarization of the steel is carried out using the potentiostat-galvanostat.

\section{Prospects for further research}

The scientific mission of further research is to determine the electrochemical characteristics of steels without surface films, with the possibility of studying their behavior at the apex of local defects. That will allow to determine the values of the protective potential for various types of shipbuilding steels in the cathodic protection of sea vessels and structures by impressed current to prevent local corrosion and mechanical destruction of these objects.

Prospects for investigating the parameters of steel protection consist in the future forecasting and management of corrosion-fatigue properties of metals.

\section{Conclusion}

The hierarchy analysis method has shown that the most effective method for investigating the metal surface under cathodic polarization is the "Laboratory experiment consisting in continuously metal surface-renewall during the entire experiment". The method for conducting polarization investigations of metals has been developed; in the course of the work, the type of the most promising reference electrode has been determined and a laboratory base for its production has been developed.

The method for determining the electrochemical characteristics of metals under cathodic polarization has been developed, which makes it possible to regulate the values of the protective potential of cathodic protection of sea vessels and structures.

\section{Acknowledgments}

The reported study was funded by RFBR and Government of the Sevastopol according to the research project № 18 -48920017.

\section{References}

[1] Ivanova, O[lga]; Dushko, V[eronika] \& Rodkina, A[nna] (2016). Experimental Researches Automation of Spatial Oscillations of the Floating Ocean Engineering Systems in the Wave Basin, Proceedings of the 26th DAAAM International Symposium, pp.1059-1067, B. Katalinic (Ed.), Published by DAAAM International, ISBN 978-3902734-07-5, ISSN 1726-9679, Vienna, Austria. DOI: 10.2507/26th.daaam.proceedings.149 
[2] Sholar, S[tanislav]; Ivanova, O[lga]; Dushko, V[eronika]; Kramar, V[adim] \& Rodkina, A[nna] (2016). Experimental Researches in the Wave Basin Using National Instruments Technology, Proceedings of the 27th DAAAM International Symposium, pp. 0417-0422, B. Katalinic (Ed.), Published by DAAAM International, ISBN 978-3-902734-08-2, ISSN 1726-9679, Vienna, Austria. DOI: 10.2507/27th.daaam.proceedings.061

[3] Nyrkov, A., Zhilenkov, A., Sokolov, S. and Chernyi, S. (2018). Hard- and Software Implementation of Emergency Prevention System for Maritime Transport, Automation and Remote Control, vol. 79, no. 1, pp. 195-202.

[4] Chernyi, S. (2018). Techniques for selecting topology and implementing the distributed control system network for maritime platforms, AKCE International Journal of Graphs and Combinatorics, Vol. 15, Issue 2, pp. 219-223.

[5] Nyrkov, A.; Goloskokov, K.; Koroleva, E.; Sokolov, S.; Zhilenkov A. and Chernyi S. (2017). Mathematical Models for Solving Problems of Reliability Maritime System, Advances in Systems, Control and Automation, pp. 387-394,.

[6] BCN 39-84 (1985). Cathodic protection against corrosion of equipment and metal structures of hydraulic structures. Minenergo of the USSR, $29 \mathrm{p}$.

[7] RD 31.35.07-83 (1983). Guidelines for electrochemical corrosion protection of metal structures of marine hydraulic structures in the underwater zone. M.: Soyuzmorniiproekt, 15 p.

[8] GOST 26501-85 (1985). Sea vessels hulls. General requirements for electrochemical protection. M.: Publishing house of standards, $8 \mathrm{p}$.

[9] Kramar, Vadim; Dushko, Veronika; Rodkina, Anna; Zaiets, Anastasiia (2015). Influence of Stress-Corrosion Fractures on Potential of Ship-Building Metals in the Sea Water. 25th DAAAM International Symposium on Intelligent Manufacturing and Automation, 2014, Guest Editor B.[ranko] Katalinic, Procedia Engineering, Volume 100, 2015, ISSN 1877-7058, 26-29th November 2014, Vienna, Austria, Published by Elsevier, Ltd. P. $1068-1074$. https://doi.org/10.1016/j.proeng.2015.01.468

[10] Dushko, V.; Rodkina, A. and Ivanova, O. (2016). Investigation of the juvenile surface of steel in seawater. The Future of Engineering Science. Nizhny Novgorod, pp. 311-312.

[11] Satti, T. and Kearns, K. Analytical planning. Organization of systems.

[12] Shikin, E.; Chkhartishvili, A. Mathematical methods and models in management.

[13] Ozhiganov Ju.G. (1980). Corrosion fatigue of metals, used in the vessel's engineering: Doctor of Engineering Science dissertation /Ozhiganov Jurij Grigor'evich. Sevastopol, 391 p.

[14] Copyright certificate SRSR №223569 cl. 48 d 11/00.

[15] Patent 93240 Ukraine, MPK7 G01N 27/30, H01M 4/34. The method of manufacturing the porous silver-chloride reference electrode /Ozhiganov Ju.G., Ozhiganov O. Ju., Lebed' E.K., Ivanova O.A.; patentee and patent owner SevNTU. - № a200813288; pat. 17.11.08; publ. 25.01.11, Bull. №2.

[16] Kramar, V[adim]; Dushko, V[eronika]; Rodkina, A[nna] \& Alchakov, V[asiliy] (2016). Neural Network Modeling the Potential of Steels with Different Chrome Content, Proceedings of the 26th DAAAM International Symposium, pp.0641-0647, B. Katalinic (Ed.), Published by DAAAM International, ISBN 978-3-902734-07-5, ISSN 1726-9679, Vienna, Austria. DOI: 10.2507/26th.daaam.proceedings.087 